\title{
Unsymmetrical Diboron Reagents: Application in Borylation Reactions of Unsaturated Bonds
}

\author{
Siyi Ding ${ }^{1}$, Liang $\mathrm{Xu}^{2} \mathbb{D}$ and Zongcheng Miao ${ }^{1, *}$ \\ 1 Key Laboratory of Organic Polymer Photoelectric Materials, School of Science, Xijing University, \\ Xi'an 710123, China; dingsiyi2009@163.com \\ 2 School of Chemistry and Chemical Engineering/Key Laboratory for Green Processing of Chemical \\ Engineering of Xinjiang Bingtuan, Shihezi University, Shihezi 832003, China; xuliang4423@shzu.edu.cn \\ * Correspondence: miaozongcheng@xijing.edu.cn; Tel.: +86-189-9115-0632
}

Academic Editor: Alejandro Baeza Carratalá

Received: 14 March 2019; Accepted: 1 April 2019; Published: 4 April 2019

check for updates

\begin{abstract}
In the past decades, borylation reactions have received extensive research interest and have developed into effective tools in the synthesis of versatile organoboron compounds. Boranes and symmetrical diboron compounds are commonly utilized as borylating reagents in these transformations, especially in the borylation reactions of unsaturated bonds. More recently, several types of unsymmetrical diboron reagents have been synthesized and applied in these borylation reactions, allowing for complementary chemo- and regioselectivity. This review aimed to highlight the recent development in this rising research field, focusing on new reactivity and selectivity that originates from the use of these unsymmetrical diboron reagents.
\end{abstract}

Keywords: diboron reagents; borylation reaction; regioselectivity; metal-catalyzed; metal-free; mechanistic study

\section{Introduction}

Organoboron compounds, especially boronic acids and their derivatives, have served as the preeminent practical building blocks for the construction of molecular complexity and diversity for decades [1]. Due to their versatile reactivity, they play a pivotal role as practical and fundamental platform molecules in synthetic organic chemistry. It has been well documented that they can be used as essential carbon nucleophiles in many types of transformations to introduce functional groups. In addition to various reactions that build up carbon-carbon bonds (e.g., Suzuki-Miyaura coupling) [2], a variety of carbon-heteroatom bonds can be constructed through the transformation of organoboron compounds (e.g., via oxidation and Chan-Lam coupling) [3,4]. This has stimulated the tremendous application of organoboron compounds in the preparation of synthetical intermediates, organic materials, fine chemicals, and drug candidates. Meanwhile, the development of efficient and convenient strategies to introduce boryl groups into readily-obtained organic feedstocks has been persistently pursued [5-12]. Given the versatility of organoboron compounds, increasing their accessibility from other readily available raw materials will not only enrich the library of borylated structural units, but also provide opportunities for rapid diversification of the raw materials.

Typically, to access organic boronic acids or boronates, there are two main pathways (Scheme 1A). One pathway takes advantage of the transformation of organic halides. The other relies on the addition of B-H or B-M (boron-metal) bonds to unsaturated compounds, such as alkenes and alkynes.

Usually starting with the organic halides, highly reactive organometallic intermediates with $\mathrm{C}-\mathrm{M}$ (carbon-metal) bonds, such as $\mathrm{C}-\mathrm{Li}$ and $\mathrm{C}-\mathrm{Mg}$ bonds, are first prepared via halogen-metal exchanges. Then, transmetalation with borates provides borylated products. Alternatively, C-M bonds can also be obtained via oxidative addition processes. In 1995, Pd-catalyzed borylation of aryl halides was 
achieved by Miyaura et al. with bis(pinacolato)diborane $\left(\mathrm{B}_{2} \mathrm{pin}_{2}\right)$ for the first time, by using the intermediary C-Pd bonds [13]. Since then, many researchers have been committed to the development of new synthetic routes to construct C-B bonds via similar strategies. The latter protocol has been used more widely than the former organometallic pathway, due to its relatively milder reaction conditions and higher functional group compatibility.

(A)

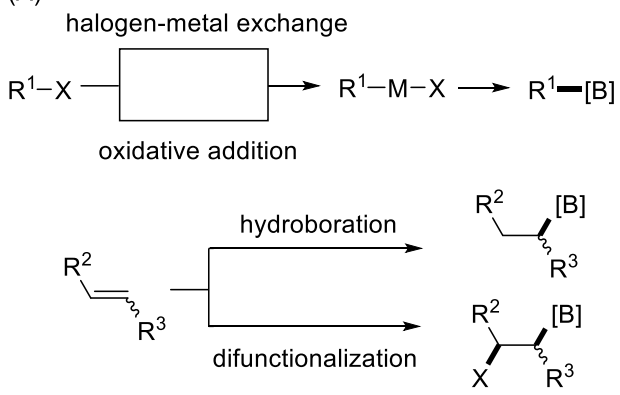

(B)

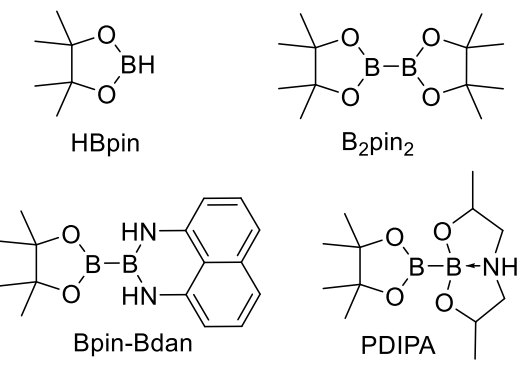

Scheme 1. (A) Two main pathways for the preparation of organoboron compounds; (B) representative borylating reagents.

When the starting materials are changed to unsaturated compounds, the addition of B-H bonds of organoboranes can be achieved via stoichiometric [14,15] or catalyzed [16] hydroboration pathways. More recently, many types of difunctionalization reactions [10-12] that incorporate boryl groups have also been studied. In these cases, diboron reagents are usually utilized as the boryl source, involving key intermediates that contain B-M bonds [17,18].

Various organoboron compounds can be accessed via the above-mentioned protocols. As for the borylating reagents (Scheme 1B), symmetric diboron reagents, especially $\mathrm{B}_{2} \mathrm{pin}_{2}$, have been utilized most frequently. Recently, unsymmetrical diboron reagents have been developed and applied in many borylation reactions with unsaturated bonds. Interesting chemo- and regioselectivity has been observed in many cases. These advances are highlighted herein, with a focus on clarifying the different selectivity for these unsymmetrical diboron reagents.

\section{2. $s p^{2}-s p^{3}$ Diboron Reagents}

An excellent review article has been published on the preparation, properties, and application of $\mathrm{sp}^{2}-\mathrm{sp}^{3}$ diboron reagents [19]. The following provides a brief summary of these types of reagents, which will not only complement the context of this topic, but will also benefit an understanding of borylation reactions.

Generally, monoquaternization of $\mathrm{sp}^{2}-\mathrm{sp}^{2}$ diboron reagents produces $\mathrm{sp}^{2}-\mathrm{sp}^{3}$ diboron reagents. Such transformations have been explored for a long time since it is not only a research interest of main group chemistry, but also the crucial conversion in the activation of various $\mathrm{sp}^{2}$-sp $\mathrm{sporylating}^{2}$ bo reagents [20,21]. The latter process is usually achieved via the assistance of additive, single Lewis bases, which produces lengthened, polarized, and more reactive B-B bonds. In the in situ generated $\mathrm{sp}^{2}-\mathrm{sp}^{3}$ diboron reagents, the nucleophilicity of the unquaternized $\mathrm{sp}^{2}$ boron atoms is enhanced, which facilitates their transfer to active metal catalysts or organic electrophiles. Therefore, broadly defined, $\mathrm{sp}^{2}-\mathrm{sp}^{3}$ diboron reagents can be seen as the active boryl source in most borylation reactions.

In 2009, a preactivated $\mathrm{sp}^{2}-\mathrm{sp}^{3}$ diboron reagent, pinacolato diisopropanolaminato diboron (PDIPA diboron), was developed by Santos et al. [22], which contained mixed $\mathrm{sp}^{2}-\mathrm{sp}^{3}$ hybridized boron atoms and a lengthened, active B-B bond. Such a structure removes the requirement for an external base in the boryl transfer process. Santos and Marder et al. [23], applied this preactiviated reagent into the copper-catalyzed $\beta$-boration of $\alpha, \beta$-unsaturated conjugated compounds, including esters, ketones, nitriles, and amides under ligand and base-free conditions (Scheme $2 \mathrm{~A}$ ). The $\mathrm{sp}^{2}$-hybridized boron 
moiety of PDIPA diboron was selectively transferred to the $\beta$-position of electron-poor olefins. Later, the same group completed a copper-catalyzed regio- and stereoselective boration of electron-deficient allenoates [24], thereby installing a boron moiety on the $\beta$-position with exclusive (Z)-double bond geometry (Scheme 2B). In all of these cases, the Bpin moiety was selectively transferred.

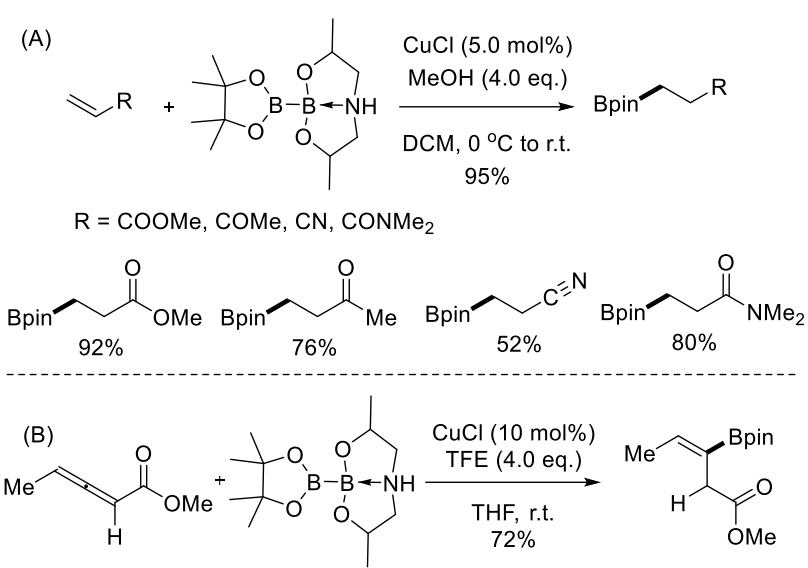

Scheme 2. Pinacolato diisopropanolaminato diboron (PDIPA diboron) in copper-catalyzed addition reactions under representative reaction conditions. (A) Using $\alpha, \beta$-unsaturated conjugated compounds as the starting materials; (B) using allenoates as the starting materials.

More recently, taking advantage of the novel $\mathrm{sp}^{2}-\mathrm{sp}^{3}$ hybridized diboron reagent and rhodium catalyst, the Aggarwal's group achieved the first Markovnikov asymmetric hydroboration of inactivated terminal alkenes (Schemes 2 and 3) [25]. In this reaction, very high levels of regioselectivity and enantioselectivity could be obtained without the need for directing groups or electronically biased alkenyl substrates. A variety of the functional groups were compatible with the obtained reaction conditions, and many terminal alkenes underwent the hydroboration process easily, except for 1,1-disubstituted alkenes and conjugated diene. The reaction was designed as an interrupted diboration reaction. Commonly, after the insertion of a Rh-B bond into carbon-carbon double bonds, a secondary $\mathrm{C}-\mathrm{B}$ bond could be introduced via $\sigma$-bond metathesis between the terminal Rh(III)-alkyl species and an $\mathrm{sp}^{2}-\mathrm{sp}^{2}$ diboron reagent. This process was inhibited when an $\mathrm{sp}^{2}-\mathrm{sp}^{3}$ diboron reagent was used because one of its boron centers was coordinatively saturated, rendering metathesis unfeasible. Instead, a protodemetalation process occurred and created the desired Markovnikov hydroboration products.

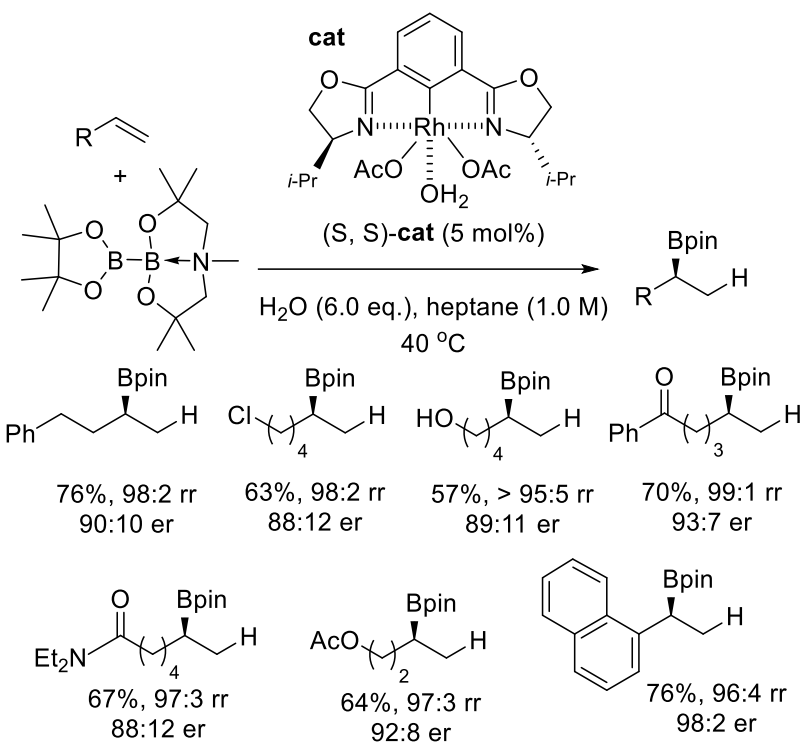

Scheme 3. Asymmetric hydroboration of unactivated terminal alkenes. 


\section{3. $s p^{2}-s p^{2}$ Diboron Reagents}

When one of the two same masking groups of symmetrical diboron reagents, such as $\mathrm{B}_{2} \mathrm{pin}_{2}$, is replaced by another bidentate ligand, an unsymmetrical $\mathrm{sp}^{2}-\mathrm{sp}^{2}$ diboron reagent is obtained. In this case, the two boryl moieties of the reagent will be different and, consequently, its applications in different borylation reactions will have to deal with the selectivity problems. These transformations will be discussed according to the specific types of reactions below.

\subsection{Addition Reactions: Diboration}

The $\mathrm{B}_{\mathrm{sp} 2}-\mathrm{B}_{\mathrm{sp} 2}$ hybridized unsymmetrical diboron reagent Bpin-Bdan (pinacolato-1,8diaminonaphthalenato diboron) was developed by Suginome et al., who applied this reagent into the Iror Pt-catalyzed addition reactions of alkynes [26]. This diboration transformation yielded differentiated 1,2-diboronylalkenes, with Bdan groups incorporated into the terminal carbon regioselectivity (Scheme 4A). It is worth mentioning that the regioselectivity of the reactions stayed high, regardless of the variation of the electronic and steric factors in the alkynes. The electron-withdrawing and -donating functional groups on the aryl groups were well-tolerated. The 2-thiophenyl and aliphatic terminal alkynes also resulted in corresponding regioselective products.

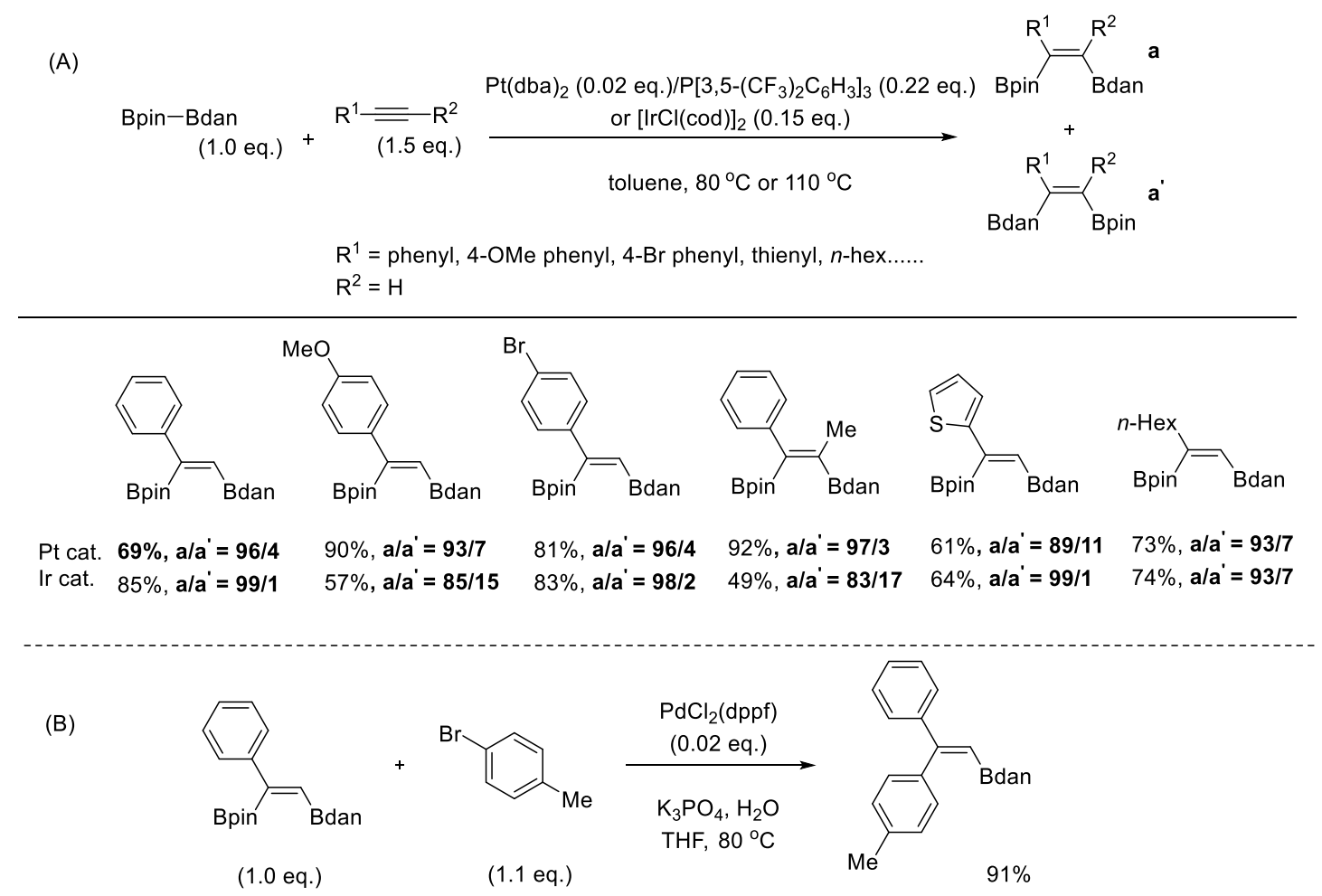

Scheme 4. (A) Using unsymmetrical diboron reagent Bpin-Bdan in the Ir- or Pt-catalyzed diboration of alkynes with Bpin-Bdan; (B) The diborylated compound using in the Suzuki-Miyaura coupling reaction.

In addition, the two incorporated boryl moieties, Bpin and Bdan, could be easily differentiated in the following Suzuki-Miyaura coupling reactions, where Bpin, at the internal position, reacted preferentially (Scheme $4 \mathrm{~B}$ ). Such selectivity was contrary to the situation when both boryl groups were Bpin units.

During the preparation of this manuscript, Huang, Liu, and Peng disclosed a similar diboration process of terminal alkyl alkynes [27]. In this approach, no noble catalyst was used, and $\mathrm{LiOH}$ was utilized as the catalyst. A highly regio- and stereoselectivity was observed. Two boryl groups of Bpin-Bdan were incorporated into carbon-carbon triple bond in cis fashion. Unlike the Ir- or 
Pt-catalyzed approach, the Bdan moiety was incorporated at the internal position. In spite of this difference, the prior reactivity of Bpin in the Suzuki-Miyaura coupling remained unchanged. Trisubstituted alkenes could be obtained via the chemoselective sequential cross-coupling reactions (Scheme 5).

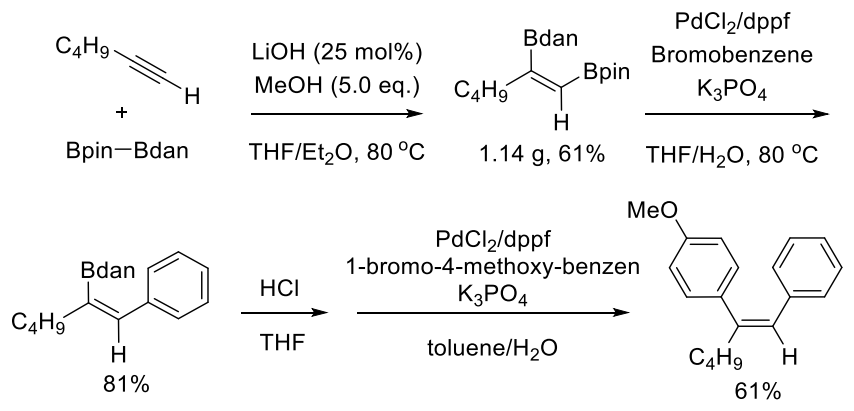

Scheme 5. LiOH-catalyzed diboration of alkynes and its application.

Uchiyama et al. described an unprecedented trans-selective diboration reaction of propargylic alcohols through a pseudo-intramolecular reaction [28]. Heteroatoms were installed on the acetylene skeleton to coordinate and activate B-B bonds of diboron reagents, in order to reduce activation energy. The propargyl alkoxides were first prepared by deprotonation between propargyl alcohols and bases. The interaction between the formed anion and a diboron compound allowed the direct diboration of the C-C triple bond without any catalyst, creating a product containing the oxaborole ring unit. When Bpin-Bdan was used as the borylating reagent, the reaction produced the vinyldiboronates in a stereoand chemoselective manner (Scheme 6).
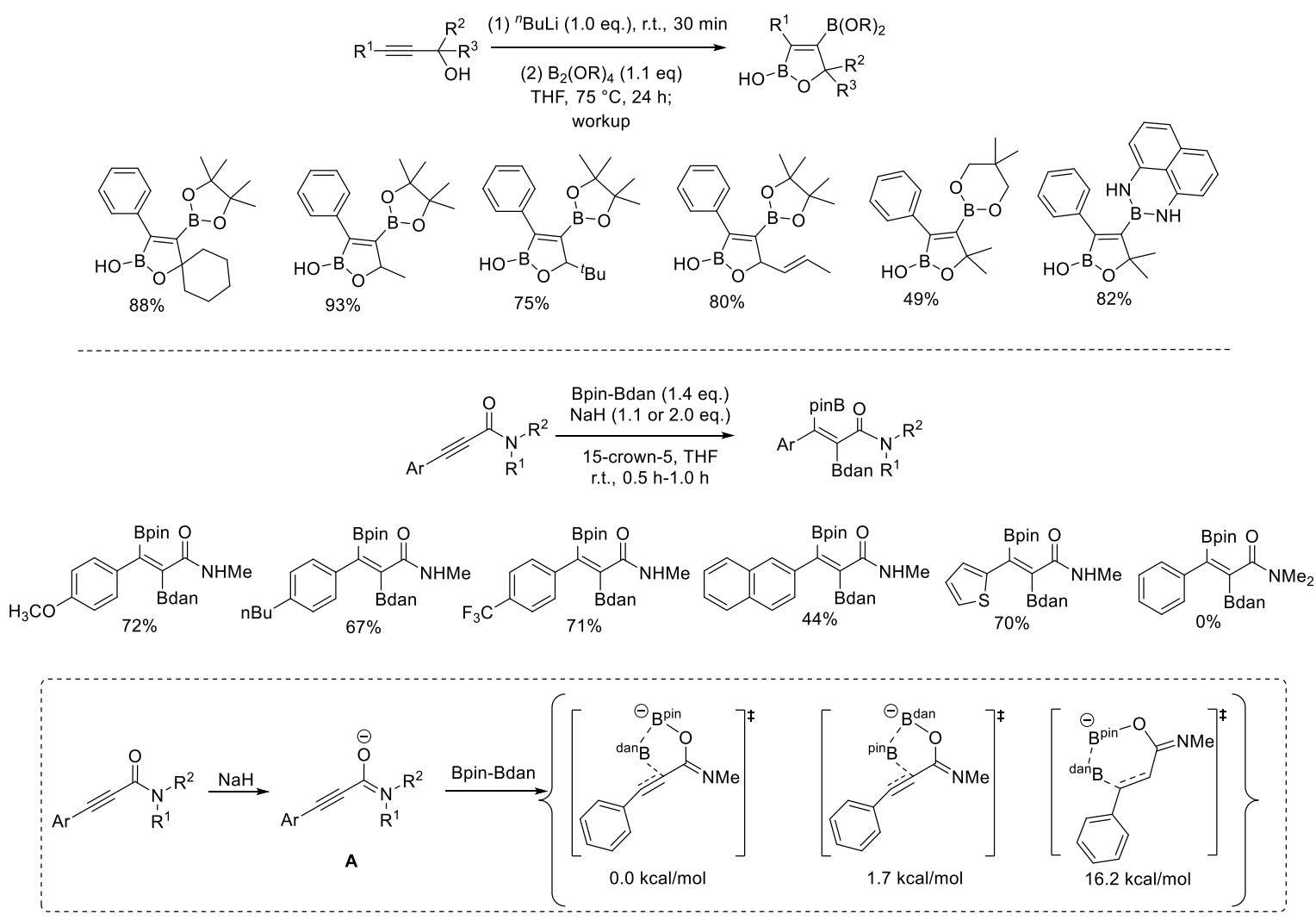

Scheme 6. Substrate-assisted diboration of alkynes with Bpin-Bdan.

In 2017, Santos et al. reported a substrate-assisted, transition-metal-free diboration reaction of alkynamides with Bpin-Bdan (Scheme 6) [29]. The installation of an amide directing group was used 
to control selectivity. The diboration transformation proceeded in a highly regio- and stereoselective fashion, and exclusively produced trans-vinyldiboronates. Bdan and Bpin were installed at the $\alpha$-and $\beta$-carbon atoms of alkynamides, separately, in moderate to excellent yields, whose chemoselective arylation would produce densely-functionalized alkenes.

A density functional theory (DFT) study was performed to probe the reaction mechanism. Deprotonation of $\mathrm{N}-\mathrm{H}$ in alkynamides with sodium hydride generated the charged Lewis base A, a naked anion with the metal counterion chelated by a crown ether. Thus, the difference in Lewis acidity of the two boron atoms in Bpin-Bdan could facilitate the selective complexation of base $\mathbf{A}$ to the Bpin moiety. With such an assistive effect, the transfer of the Bdan group to the $\alpha$-carbon atom was favored (relative $0.0 \mathrm{kcal} / \mathrm{mol}$ ), compared with the more energy-demanding $\beta$-carbon attack pathway $(16.2 \mathrm{kcal} / \mathrm{mol})$. Finally, an intramolecular bind between the resulting anion and Bpin produced the target product.

In addition to Bpin-Bdan, unsymmetrical Bpin-BMes 2 could also be employed in the diboration of alkynes, which was disclosed by Yamashita et al. in 2016 [30]. A simple treatment of the aromatic and aliphatic terminal alkynes with Bpin-BMes 2 in toluene resulted in two cis-isomers of diborated products. In the presence of a catalytic amount of ${ }^{\mathrm{n}} \mathrm{BuLi}$, the selectivity was altered and trans-diboration products resulted. When internal alkynes were used, tetrasubstituted syn-diborylalkenes could be obtained, in spite of lower reaction rates (Scheme 7).

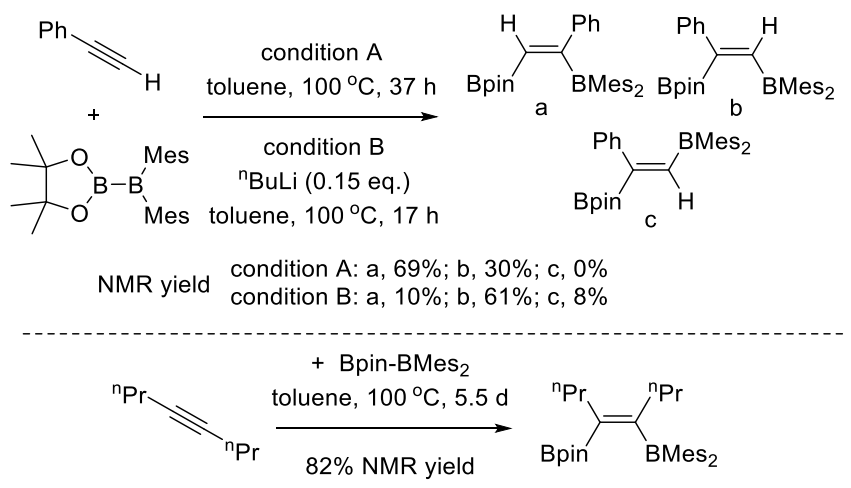

Scheme 7. Bpin-BMes 2 in the diboration of alkynes.

In 2015, Santos et al. disclosed a platinum-catalyzed regio- and chemoselective diboration of 1,1-disubstituted allenes, using Bpin-Bdan as the borylating reagent and producing vinyl and allyl boronates in good to excellent yields (Scheme 8) [31]. Chemoselective transfer of the Bpin moiety to the internal sp-hybridized carbon atom was observed. The Bdan moiety was incorporated into the terminal unsubstituted carbon atom. It should be noted that the ratios of several obtained isomers could be adjusted and even overturned, depending on the structure of the starting materials (a choice of catalyst and ligand combinations).

In 2015, Fernández et al. reported a diboration reaction of olefins using Bpin-Bdan, under metal-free conditions (Scheme 9) [32]. Both terminal and internal alkenes were suitable starting materials. When the former type of substrates was used, the Bdan moiety was incorporated into the internal position with high regioselectivity preference. Mechanistically, Lewis acid-base adducts were formed in the beginning via the interaction between the alkoxide anion and the one boron atom of Bpin-Bdan to form the corresponding diborated alkenes. Due to the $\pi$-donation from the nitrogen lone pair to the boron orbital in the Bdan moiety, the boron atom of the Bpin moiety has a stronger Lewis acidity and, hence, a stronger affinity with alkoxide. Then, a selective nucleophile transfer was possible to deliver Bdan to the olefins. As for the substrate scope, allylbenzene, vinylcyclohexane, chain internal olefins, cis-3-hexene, and cyclic olefins were all suitable starting materials. Furthermore, the addition of cyclic olefins with Bpin and Bdan moieties took place in syn fashion. However, vinylarenes failed to undergo the diboration process. 


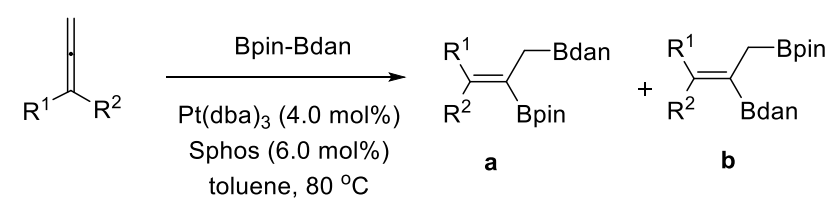

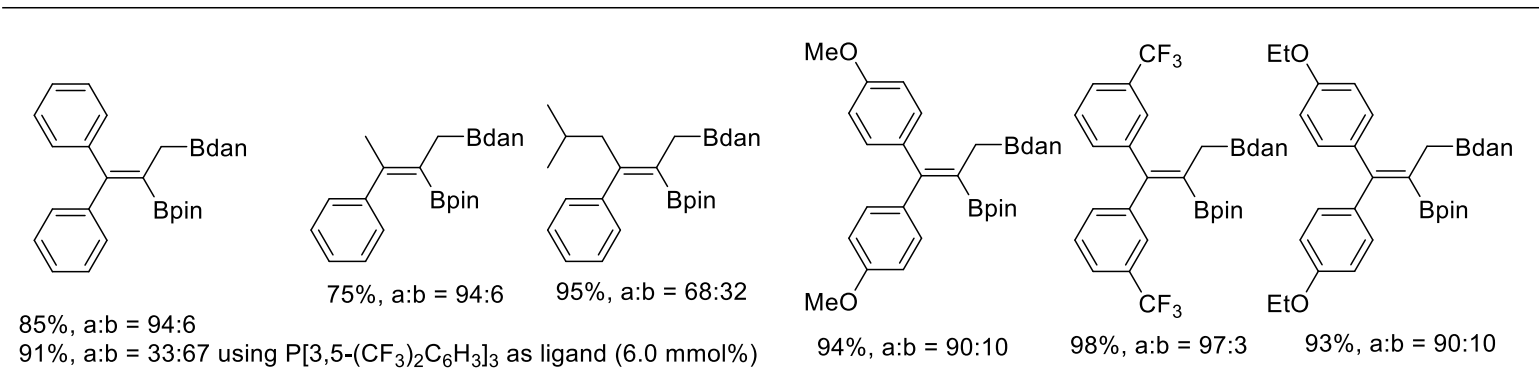

Scheme 8. Pt-catalyzed diboration of allenes.

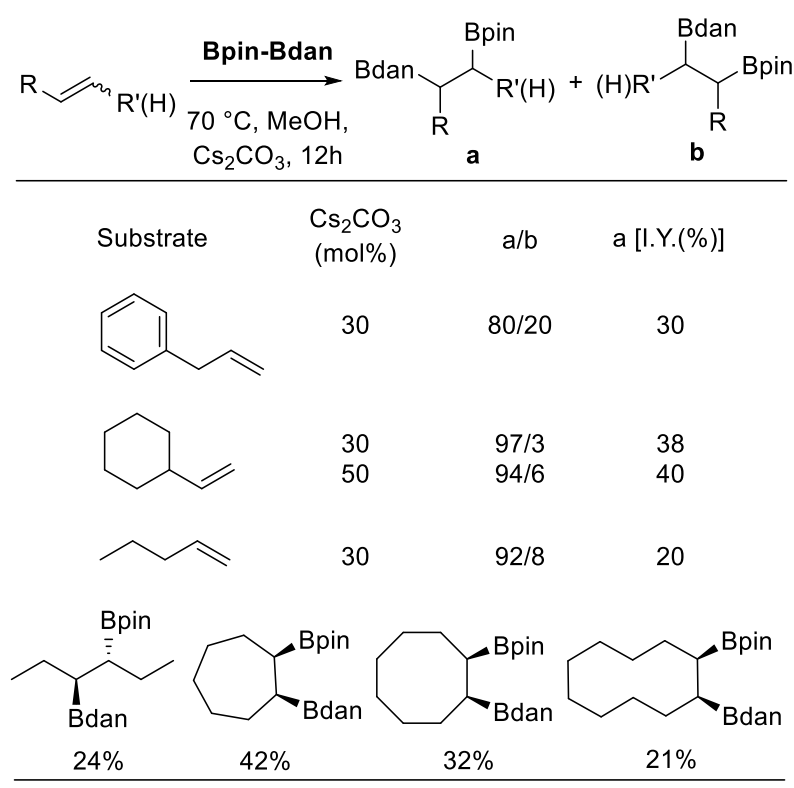

Scheme 9. Diboration of alkenes.

Fernández et al. also studied the diboration reaction of diazo compounds, which were prepared in situ from $N$-tosylhydrazones of aldehydes and ketones, using Bpin-Bdan [33]. After the metal-free process, the different boryl moieties of the mixed diboron reagent were both connected to the former $\mathrm{sp}^{2}$ carbon atoms of the diazo compounds, producing gem-diborated products (Scheme 10). A concerted, yet asynchronous reaction pathway was proposed based on DFT calculation.

In 2017, taking advantage of a cyclohexyl-substituted pyridine(diimine) cobalt methyl complex, Chirik et al. described the 1,1-diboration of readily available terminal alkynes using diboron reagents (Scheme 11) [34]. Such an addition reaction contrasted all other previously reported transition metal-catalyzed 1,2-diboration reactions. In this reaction, 1,1-Diboron olefins containing two identical or two different boryl groups could be obtained, using symmetrical (Bpin-Bpin) or unsymmetrical (Bpin-Bdan) diboron reagents separately. When using the mixed diboron reagent, the reactions proceeded efficiently and stereoselectively to produce trisubstituted olefins. The resultant chemically-differentiated boron substituents allowed for selective Suzuki-Miyaura coupling reactions, leaving Bdan intact. 


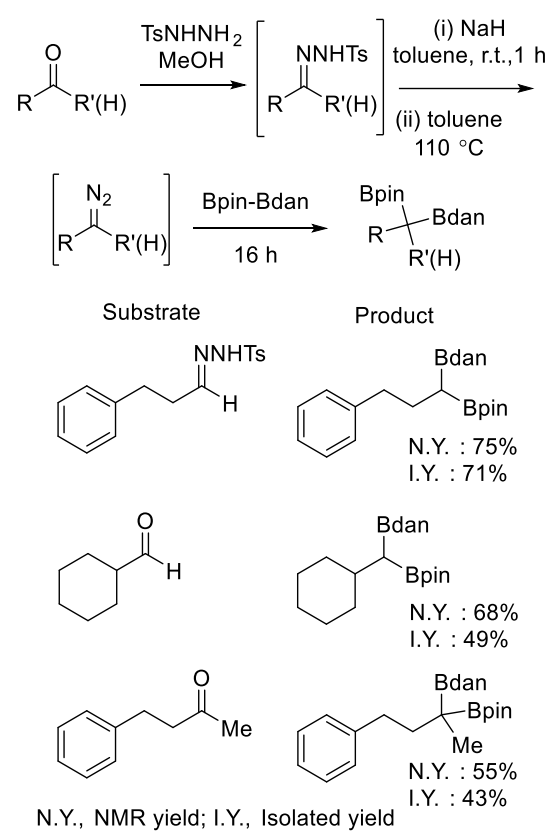

Scheme 10. Diboration of aldehydes and ketones with Bpin-Bdan.

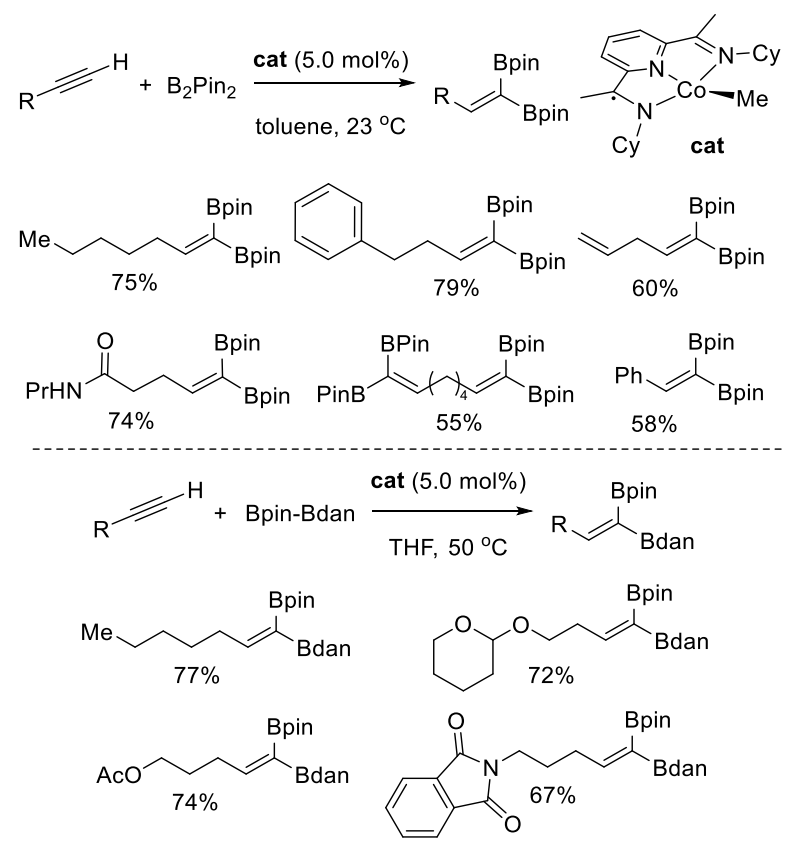

Scheme 11. Cobalt-catalyzed 1,1-diboration of terminal alkynes.

\subsection{Addition Reactions: Hydroboration}

Fernández, Carbó and Cid studied the application of Bpin-Bdan in organocatalytic $\beta$-boration of $\alpha, \beta$-unsaturated carbonyl compounds in 2014 (Scheme 12) [35]. In the presence of a suitable base, selective activation of Bpin-Bdan with alkoxide was achieved, giving an $\mathrm{MeO}^{-} \rightarrow$ Bpin-Bdan adduct, which was demonstrated to be favorable compared with the $\mathrm{MeO}^{-} \rightarrow$ Bdan-Bpin adduct both experimentally and theoretically. Then, the Bdan moiety was directly transferred to the $\beta$-positions of the activated $\mathrm{C}-\mathrm{C}$ bonds as a formal boron nucleophile with regioselectivity. This selectivity was also derived from the Lewis acidity difference of the two boron atoms, as mentioned above. The same strategy was then applied to the $\beta$-boration of $\alpha, \beta$-unsaturated imines formed in situ [36]. An asymmetric version of this type of transformation was also described via the assistance of chiral phosphines. 


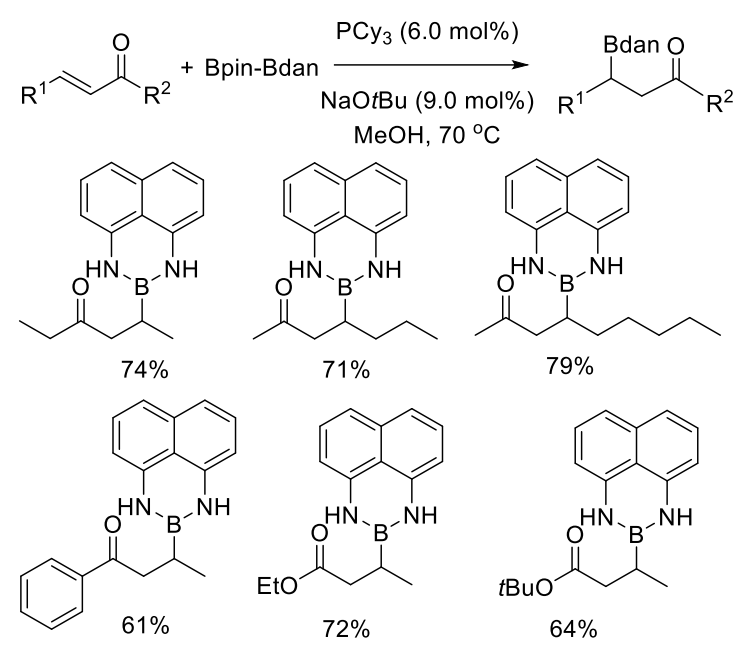

Scheme 12. Organocatalytic $\beta$-boration of $\alpha, \beta$-unsaturated carbonyl compounds with Bpin-Bdan.

Copper-catalyzed borylation reactions of unsaturated compounds, such as alkenes, alkynes, and arynes, have been well-developed as a relatively cheap method to incorporate boryl groups. A variety of reactions involving the addition of boryl groups, including hydroboration, diboration, borylstannylation, and carboboration, have been studied, which enabled a quick access to highly functionalized organoboron compounds.

Commonly, borylcopper species $\mathrm{A}$, containing a $\mathrm{Cu}-\mathrm{B}$ single bond, is considered to be the active catalyst in borylation reactions [12]. Subsequent insertion of a carbon-carbon triple or double bond into the $\mathrm{Cu}-\mathrm{B}$ bond generates a $\beta$-boryl organocopper species $\mathrm{B}$, which is followed by a reaction with an electrophile to produce the intermediate $C$, which then reacts with $B_{2} p_{i n}$ to accomplish the catalytic process. When Bpin-Bdan is used as the borylating reagent in such reactions, a $\mathrm{Cu}-\mathrm{Bdan}$ species will be generated via $\sigma$-bond metathesis first, due to the selective interaction between the more Lewis acidic Bpin moiety and the alkoxy moiety of the precatalyst, $\mathrm{Cu}-\mathrm{OR}$. The transformation will add the Bdan unit to the unsaturated bonds (Scheme 13). More importantly, the $\mathrm{Cu}-\mathrm{Bdan}$ species, in combination with suitable catalysts and ligands, is able to provide completely different regioselectivity compared with the traditional the $\mathrm{Cu}$-Bpin species. This will be detailed hereinafter.
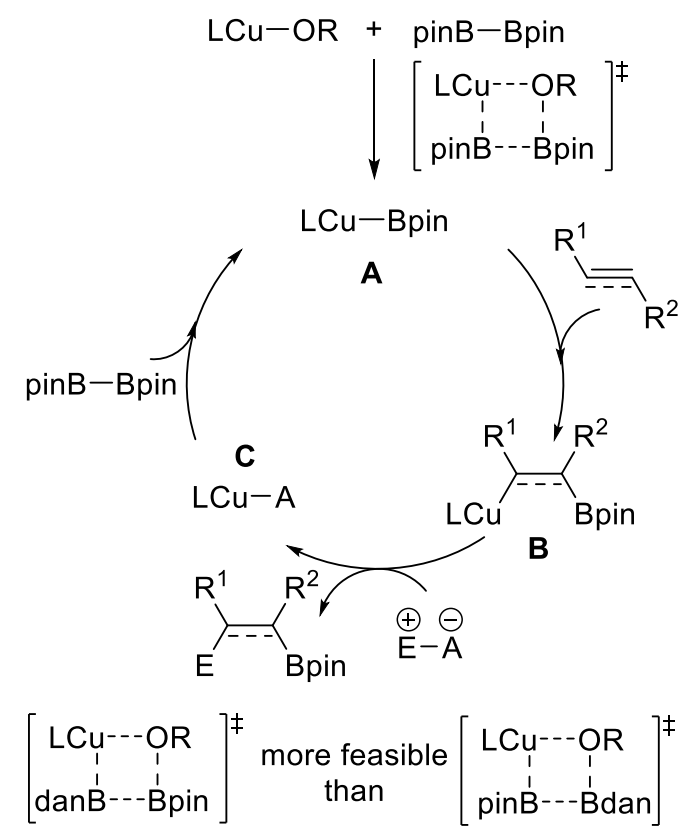

Scheme 13. Mechanism of Cu-catalyzed boration of alkenes and alkynes. 
In 2014, Yoshida et al. developed the first general $\alpha$-selective formal hydroboration of terminal alkynes (Scheme 14) [37]. Accordingly, diverse branched alkenylboron compounds were obtained exclusively. The use of Bpin-Bdan as the boryl source in the presence of a $\mathrm{Cu}-\mathrm{NHC}$ ( $\mathrm{N}$-heterocyclic carbene) catalyst was essential to convert the common $\beta$-selectivity with $B_{2}$ pin $_{2}$. Regardless of the electronic and steric nature of terminal alkynes employed, Markovnikov-type hydroboration products could be obtained in high yield and with high regioselectivity.

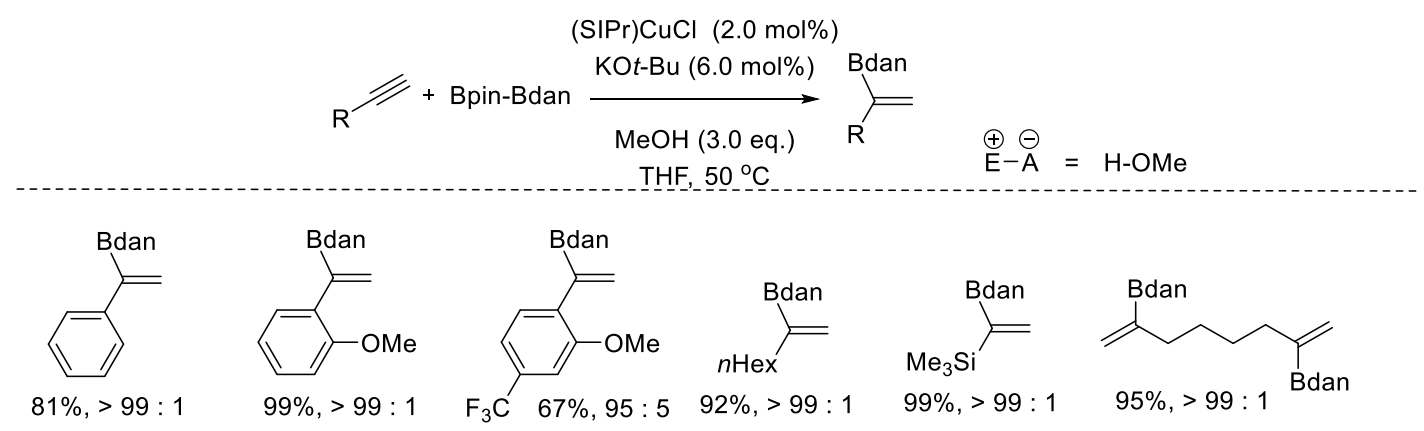

Scheme 14. Cu-catalyzed hydroboration of terminal alkynes.

Later, another protocol for hydroboration of alkynes with Bpin-Bdan was disclosed by Santos et al. (Scheme 15) [38]. In this case, activated alkynes, such as alkynoates and alkynamides, were utilized. Aqueous and open-air conditions made this copper(II)-catalyzed process operationally feasible and simple. The reaction also proceeded in a remarkably chemo-, regio-, and stereoselective manner, producing (Z)- $\beta$-Bdan enoates and enamides in good-to-excellent yields.

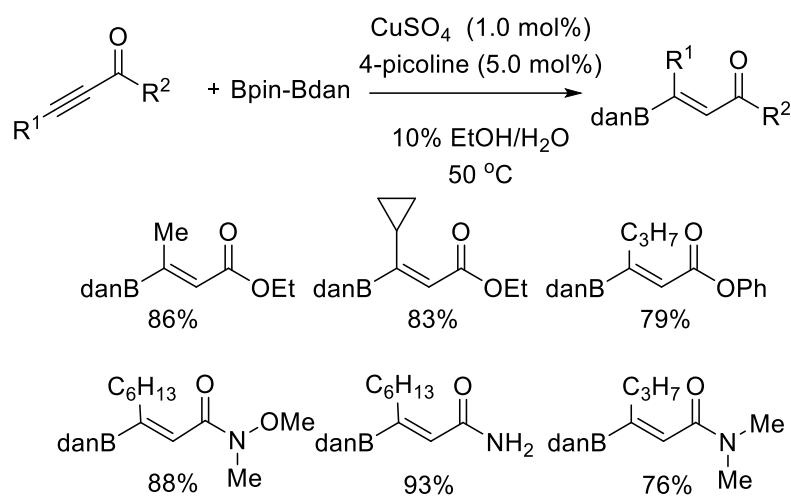

Scheme 15. Cu-catalyzed hydroboration of alkynoates and alkynamides.

\subsection{Other Types of Addition Reactions}

As mentioned above, the $\mathrm{Cu}-\mathrm{Bdan}$ species could be added to terminal alkynes in a regioselective manner, which was inverse to the selectivity of the $\mathrm{Cu}$-Bpin species. Taking advantage of this property, Yoshida et al. performed a Cu-catalyzed, three-component coupling reaction, which created borylstannylated products of alkynes (Scheme 16) [39]. Inverse regioselectivity was observed when using Bpin-Bdan, compared with $\mathrm{B}_{2}$ pin $_{2}$ [40]. $\mathrm{Bu}_{3}$ SnOMe was used to supply the stannyl group and to capture the $\mathrm{Cu}-\mathrm{C}$ bonds as an electrophile, as indicated in Scheme 13. A variety of cis-boryl(stannyl)alkenes could be easily prepared from terminal alkynes. In addition, allenes were also used as starting materials, and also underwent regio- and stereoselective borylstannylation reactions to provide (Z)-1-stannyl-2-boryl-2-alkenes. In this case, the Bdan moiety was transferred to the internal sp-hybridized carbon atom of allenes. 


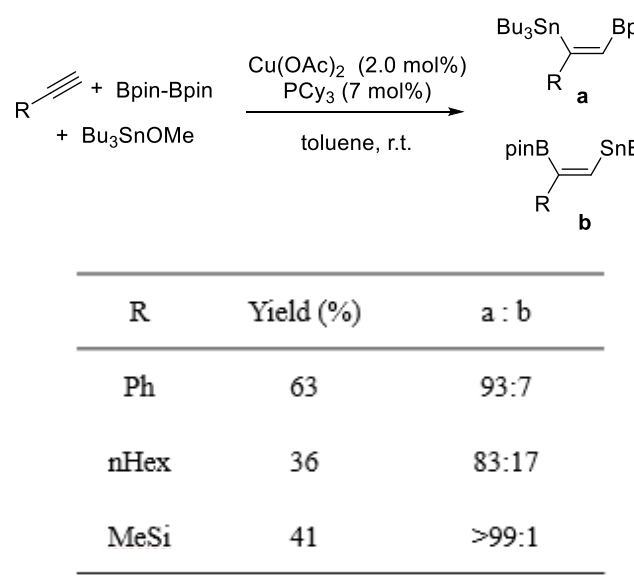

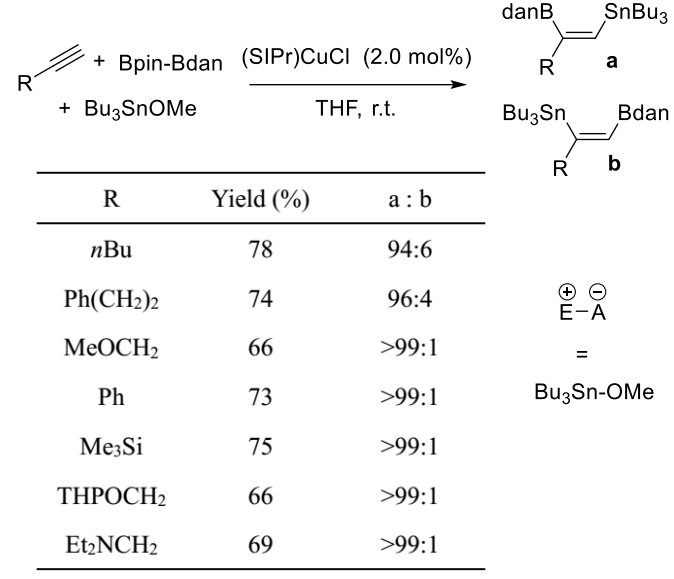

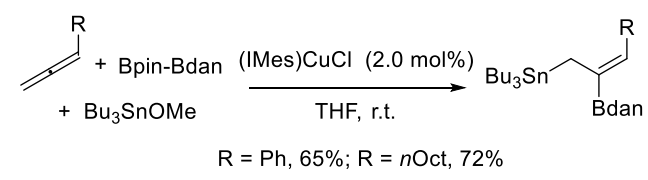

Scheme 16. Cu-catalyzed borylstannylation of alkynes and allenes.

In 2014, Miura et al. performed a copper-catalyzed three-component reaction, which achieved the aminoboration of bicyclic alkenes with diboron reagents $\left(\mathrm{B}_{2} \mathrm{pin}_{2}\right.$ or Bpin-Bdan) as the nucleophilic boron source and hydroxylamines as the amination reagent [41]. Two effective catalytic systems that promote this transformation were described after extensive screening of reaction variables without the formation of ring-opened byproducts. Various bicyclic alkenes, including oxa- and azabicycloalkenes, were suitable starting materials for this stereoselective aminoboration transformation. When $\mathrm{B}_{2} \mathrm{pin}_{2}$ was used, the difunctionalized products were less stable in several cases, which made the purification step problematic. To solve this problem, the crude materials were converted into the more stable Bdan derivatives, enabling the corresponding products to be isolated by column chromatography. Several examples that directly harnessed Bpin-Bdan as the borylating reagent were also explored. Similarly, the Bdan moiety was selectively transferred to alkenes (Scheme 17).

Later, the same authors described a Cu-catalyzed aminoboration of unactivated terminal alkenes [42]. Interestingly, regioselectivity could be well regulated by a suitable combination of employed ligands and diboron reagents. According to the data on reaction condition screening, in the presence of $\mathrm{B}_{2}$ pin $_{2}$, the change of ligands alone could result in opposite regioselectivity. As indicated in Scheme 18, with isolated $\mathrm{Cu}($ xantphos) $\mathrm{Cl}$ and $\mathrm{NaO} t \mathrm{Bu}$ as the precatalyst and base, respectively, the terminally-borylated products have good yield with high regioselectivity (93:7). Conversely, a series of NHC ligands primarily led to the opposite regioisomer and IPr produced the highest regioselectivity (4:96). However, the yield of such an aminoboration reaction was poor (24\%). When the borylating reagent was replaced with Bpin-Bdan, the reaction was improved significantly with a greatly increased yield and the maintenance of the unique regioselectivity. With these two conditions, a variety of valuable $\beta$-borylalkylamines were obtained regiodivergently. 


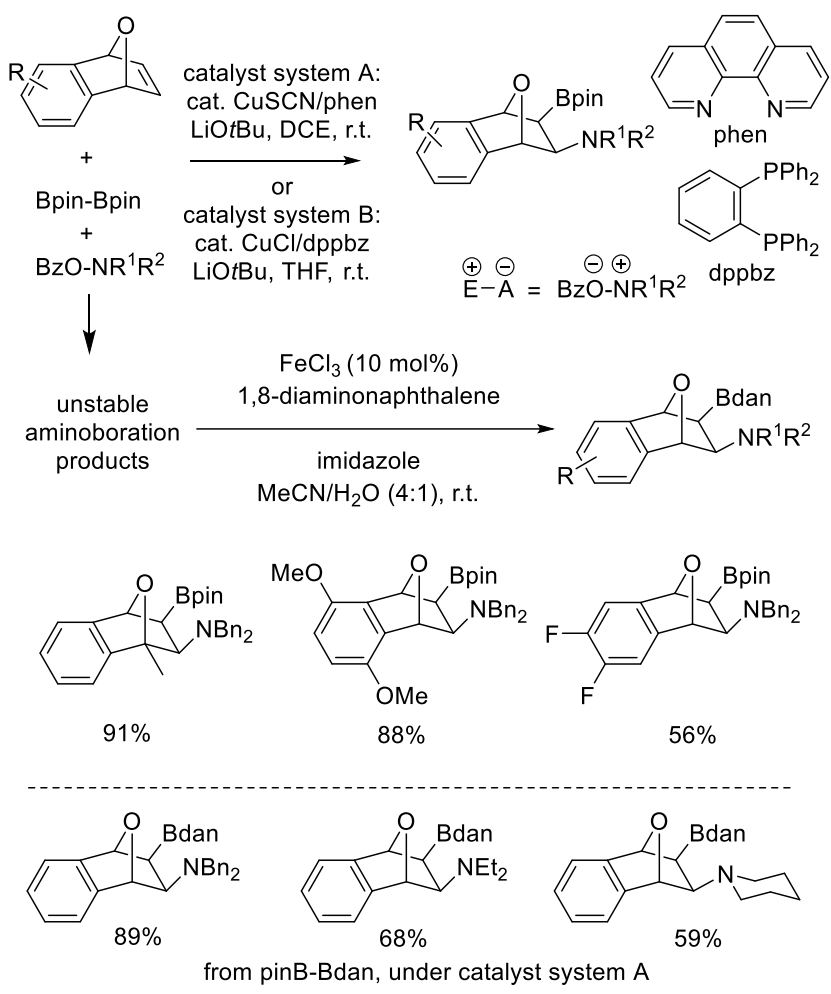

Scheme 17. Cu-catalyzed aminoboration of bicyclic alkenes.

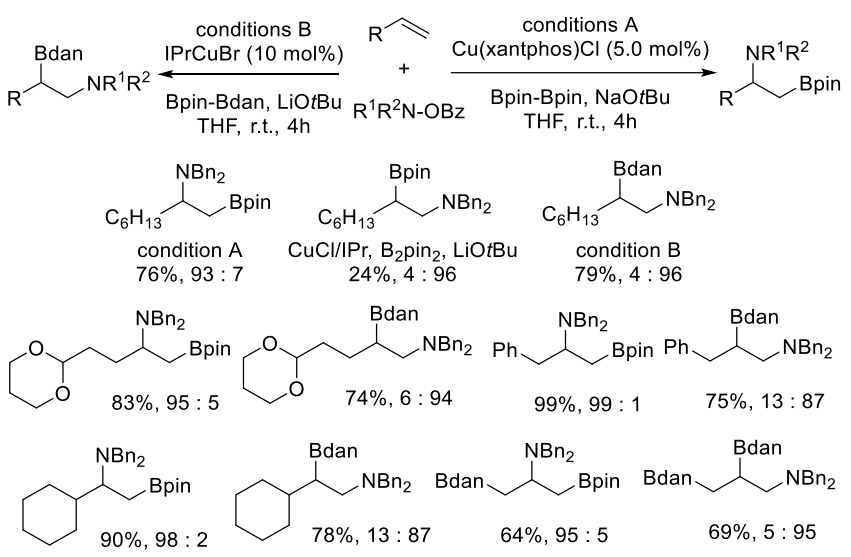

Scheme 18. Regiodivergent $\mathrm{Cu}$-catalyzed aminoboration of terminal alkenes.

In 2016, another aminoboration of alkenes reaction was described by Miura et al. [43]. In this case, alkenyl 1,8-diaminonaphthyl (DAN) boronates were used as the starting materials (Scheme 19). The reaction proceeded in a regio- and stereoselective fashion to form the corresponding $\beta$-boryl- $\alpha$-aminoboronic acid derivatives. The exploration began with (E)-2-octenyl DAN boronate, $\mathrm{B}_{2} \mathrm{pin}_{2}$, and $\mathrm{O}$-benzoyl- $\mathrm{N}, \mathrm{N}$-dibenzylhydroxylamine. An extensive screening of reaction parameters demonstrated that the aminoboration proceeded smoothly at room temperature in the presence of a combination of $\mathrm{Cu}(\mathrm{OAc})_{2}, 1,3-\mathrm{Bis}$ (diphenylphosphino)propane (dppp), and $\mathrm{LiOtBu}$. A high syn/anti diastereoselectivtiy (99:1) was observed. Due to the instability of the obtained products, in situ oxidation by $\mathrm{NaBO}_{3} \cdot \mathrm{H}_{2} \mathrm{O}$ was applied to facilitate the isolation of products. Another solution to solve the instability problem relied on the utilization of Bpin-Bdan. The standard $\mathrm{Cu}(\mathrm{OAc})_{2} / \mathrm{dppp}$ catalyst system used for $B_{2}$ pin $_{2}$ was also suitable for Bpin-Bdan. Then, the more stable and easily handled Bdan moiety was introduced to the products, directly isolating the formed $\beta$-Bdan- $\alpha$-aminoboronic DAN boronates. 

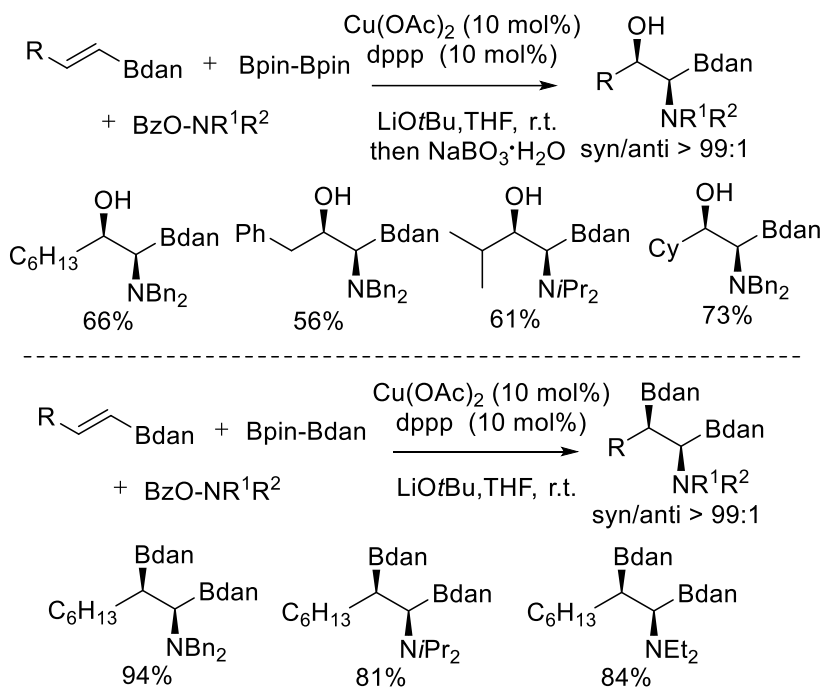

Scheme 19. Cu-catalyzed aminoboration of alkenylboronates.

In 2017, Yoshida et al. described the first Cu-catalyzed Bdan-installing carboboration reaction using Bpin-Bdan [44]. Under CuCl/dppf (1,1'-Bis(diphenylphosphino)ferrocene) catalysis, a direct and regioselective approach to produce alkylboron compounds was established via three-component reactions (Scheme 20). As for the substrate scope, carbon-carbon double bonds attached to silicon atoms exhibited superior reactivity. Various substituted vinylsilanes underwent the carboboration reactions in a chemoselective and regioselective fashion. In addition, a vinylborane was also found to be a suitable starting material, and produced 1,2-diborylalkane bearing differentiated masked Bdan and Bpin boryl moieties.

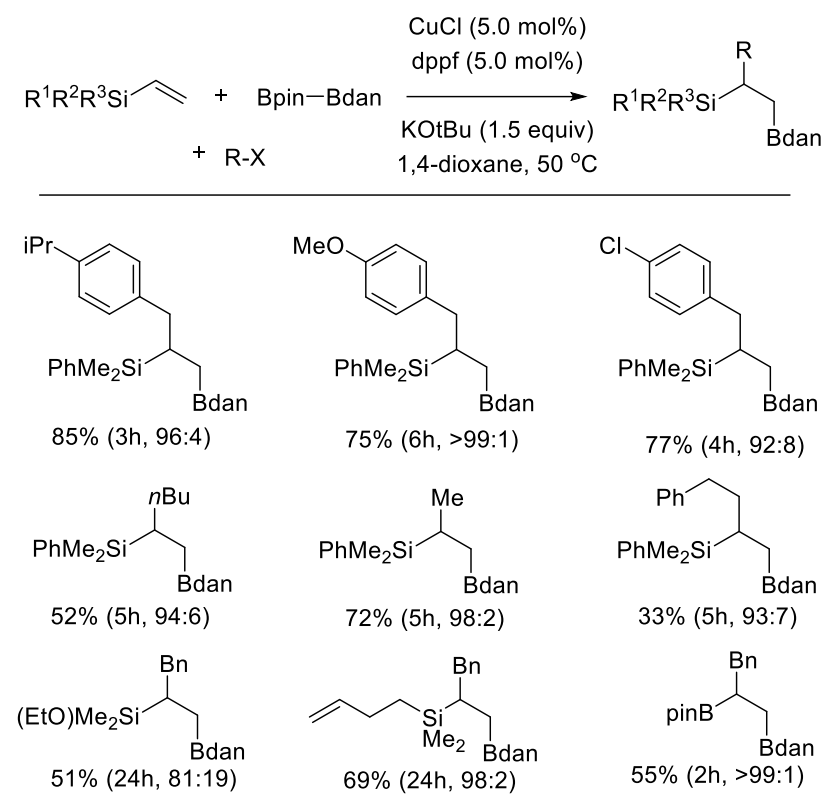

Scheme 20. Cu-catalyzed carboboration of alkenes.

\section{Conclusions}

Unsymmetrical diboron reagents, whether $\mathrm{sp}^{2}-\mathrm{sp}^{3} \mathrm{or}_{\mathrm{sp}} \mathrm{s}^{2} \mathrm{sp}^{2}$ hybridized, have been shown to be suitable borylating reagents in a variety of addition reactions, such as hydroboration and difunctionalization of alkenes or alkynes. Both metal-catalyzed and metal-free approaches for these transformations have been well established, offering diverse, densely functionalized alkyl and alkenyl boronic derivatives. Notably, the different regioselectivity of unsymmetrical diboron 
reagents compared with that of common symmetrical diboron reagents shows the potential of these borylating reactions to complement the existing borylating methods. In spite of these achievements, some problems still need to be addressed. First, the most commonly used Bpin-Bdan reagent usually transfers its Bdan to any unsaturated bonds. The obtained products will require additional deprotection steps to continue the transformation to relatively active boron species. Therefore, the development of the new masking groups is still very useful. In addition, the mechanism of the above-mentioned reactions still needs to be clarified, such as the driving force of the observed regioselectivity, and the cooperation and interaction of catalysts, ligands and substrates.

Author Contributions: S.D. and L.X. wrote the main article, Z.M. revised the manuscript.

Funding: This research was funded by the Special Fund for Talent Research of Xijing University, Grant number XJ17B01 and the Scientific Research Program Funded by Shaanxi Provincial Education Department (Program No. 18JK1196).

Acknowledgments: We thank LetPub (www.Letpub.com) for its linguistic assistance during the preparation of this manuscript.

Conflicts of Interest: The authors declare no conflict of interest.

\section{References}

1. Fyfe, J.W.B.; Watson, A.J.B. Recent Developments in Organoboron Chemistry: Old Dogs, New Tricks. Chem 2017, 3, 31-55. [CrossRef]

2. Lennox, A.J.; Lloyd-Jones, G.C. Selection of boron reagents for Suzuki-Miyaura coupling. Chem. Soc. Rev. 2014, 43, 412-443. [CrossRef] [PubMed]

3. Qiao, J.; Lam, P. Copper-Promoted Carbon-Heteroatom Bond Cross-Coupling with Boronic Acids and Derivatives. Synthesis 2010, 2011, 829-856. [CrossRef]

4. Sanjeeva Rao, K.; Wu, T.-S. Chan-Lam coupling reactions: Synthesis of heterocycles. Tetrahedron 2012, 68, 7735-7754. [CrossRef]

5. Ros, A.; Fernández, R.; Lassaletta, J.M. Functional group directed C-H borylation. Chem. Soc. Rev. 2014, 43, 3229-3243. [CrossRef] [PubMed]

6. Neeve, E.C.; Geier, S.J.; Mkhalid, I.A.I.; Westcott, S.A.; Marder, T.B. Diboron(4) Compounds: From Structural Curiosity to Synthetic Workhorse. Chem. Rev. 2016, 116, 9091-9161. [CrossRef]

7. Xu, L.; Wang, G.; Zhang, S.; Wang, H.; Wang, L.; Liu, L.; Jiao, J.; Li, P. Recent advances in catalytic C-H borylation reactions. Tetrahedron 2017, 73, 7123-7157. [CrossRef]

8. Yan, G.; Huang, D.; Wu, X. Recent Advances in C-B Bond Formation through a Free Radical Pathway. Adv. Synth. Catal. 2017, 360, 1040-1053. [CrossRef]

9. Chen, K.; Wang, L.; Meng, G.; Li, P. Recent Advances in Transition-Metal-Free Aryl C-B Bond Formation. Synthesis 2017, 49, 4719-4730.

10. Cuenca, A.B.; Shishido, R.; Ito, H.; Fernández, E. Transition-metal-free B-B and B-interelement reactions with organic molecules. Chem. Soc. Rev. 2017, 46, 415-430. [CrossRef] [PubMed]

11. Zhao, F.; Jia, X.; Li, P.; Zhao, J.; Zhou, Y.; Wang, J.; Liu, H. Catalytic and catalyst-free diboration of alkynes. Org. Chem. Front. 2017, 4, 2235-2255. [CrossRef]

12. Hemming, D.; Fritzemeier, R.; Westcott, S.A.; Santos, W.L.; Steel, P.G. Copper-boryl mediated organic synthesis. Chem. Soc. Rev. 2018, 47, 7477-7494.

13. Ishiyama, T.; Murata, M.; Miyaura, N. Palladium(0)-Catalyzed Cross-Coupling Reaction of Alkoxydiboron with Haloarenes: A Direct Procedure for Arylboronic Esters. J. Org. Chem. 1995, 60, 7508-7510. [CrossRef]

14. Brown, H.C. Hydroboration-A powerful synthetic tool. Tetrahedron 1961, 12, 117-138. [CrossRef]

15. Brown, H.C.; Gupta, S.K. 1,3,2-Benzodioxaborole, a convenient monofunctional hydroborating agent. Simple new synthesis of alkaneboronic esters and acids from olefins via hydroboration. J. Am. Chem. Soc. 1971, 93, 1816-1818. [CrossRef]

16. Männig, D.; Nöth, H. Catalytic Hydroboration with Rhodium Complexes. Angew. Chem. Int. Ed. Engl. 1985, 24, 878-879. [CrossRef] 
17. Partyka, D.V. Transmetalation of Unsaturated Carbon Nucleophiles from Boron-Containing Species to the Mid to Late d-Block Metals of Relevance to Catalytic C-X Coupling Reactions (X = C, F, N, O, Pb, S, Se, Te). Chem. Rev. 2011, 111, 1529-1595. [CrossRef]

18. Dang, L.; Lin, Z.; Marder, T.B. Boryl ligands and their roles in metal-catalysed borylation reactions. Chem. Commun. 2009, 27, 3987-3995. [CrossRef] [PubMed]

19. Dewhurst, R.D.; Neeve, E.C.; Braunschweig, H.; Marder, T.B. $\mathrm{sp}^{2}-\mathrm{sp}^{3}$ diboranes: Astounding structural variability and mild sources of nucleophilic boron for organic synthesis. Chem. Commun. 2015, 51, 9594-9607. [CrossRef] [PubMed]

20. Borner, C.; Wlecha, M.T.; Kleeberg, C. Unsymmetrical Diborane (4) Derivatives: A Comparative Study. Eur. J. Inorg. Chem. 2017, 38, 4485-4492. [CrossRef]

21. Oschmann, W.; Borner, C.; Kleeberg, C. Unsymmetrical diborane (4) derivatives by copper mediated B-B coupling. Dalton Trans. 2018, 47, 5318-5327. [CrossRef]

22. Gao, M.; Thorpe, S.B.; Santos, W.L. $\mathrm{sp}^{2}-\mathrm{sp}^{3}$ Hybridized Mixed Diboron: Synthesis, Characterization, and Copper-Catalyzed $\beta$-Boration of $\alpha, \beta$-Unsaturated Conjugated Compounds. Org. Lett. 2009, 11, 3478-3481. [CrossRef] [PubMed]

23. Gao, M.; Thorpe, S.B.; Kleeberg, C.; Slebodnick, C.; Marder, T.B.; Santos, W.L. Structure and Reactivity of a Preactivated $\mathrm{sp}^{2}-\mathrm{sp}^{3}$ Diboron Reagent: Catalytic Regioselective Boration of $\alpha, \beta$-Unsaturated Conjugated Compounds. J. Org. Chem. 2011, 76, 3997-4007. [CrossRef] [PubMed]

24. Thorpe, S.B.; Guo, X.; Santos, W.L. Regio- and stereoselective copper-catalyzed [small beta]-borylation of allenoates by a preactivated diboron. Chem. Commun. 2011, 47, 424-426. [CrossRef]

25. Smith, J.R.; Collins, B.S.L.; Hesse, M.J.; Graham, M.A.; Myers, E.L.; Aggarwal, V.K. Enantioselective Rhodium(III)-Catalyzed Markovnikov Hydroboration of Unactivated Terminal Alkenes. J. Am. Chem. Soc. 2017, 139, 9148-9151. [CrossRef]

26. Iwadate, N.; Suginome, M. Differentially Protected Diboron for Regioselective Diboration of Alkynes: Internal-Selective Cross-Coupling of 1-Alkene-1,2-diboronic Acid Derivatives. J. Am. Chem. Soc. 2010, 132, 2548-2549. [CrossRef]

27. Peng, S.; Liu, G.; Huang, Z. Mixed Diboration of Alkynes Catalyzed by LiOH: Regio- and Stereoselective Synthesis of cis-1,2-Diborylalkenes. Org. Lett. 2018, 20, 7363-7366. [CrossRef]

28. Nagashima, Y.; Hirano, K.; Takita, R.; Uchiyama, M. Trans-Diborylation of Alkynes: Pseudo-Intramolecular Strategy Utilizing a Propargylic Alcohol Unit. J. Am. Chem. Soc. 2014, 136, 8532-8535. [CrossRef] [PubMed]

29. Verma, A.; Snead, R.F.; Dai, Y.; Slebodnick, C.; Yang, Y.; Yu, H.; Yao, F.; Santos, W.L. Substrate-Assisted, Transition-Metal-Free Diboration of Alkynamides with Mixed Diboron: Regio- and Stereoselective Access to trans-1,2-Vinyldiboronates. Angew. Chem. Int. Ed. 2017, 56, 5193-5197. [CrossRef]

30. Kojima, C.; Lee, K.-H.; Lin, Z.; Yamashita, M. Direct and Base-Catalyzed Diboration of Alkynes Using the Unsymmetrical Diborane(4), pinB-BMes 2 . J. Am. Chem. Soc. 2016, 138, 6662-6669. [CrossRef]

31. Guo, X.; Nelson, A.K.; Slebodnick, C.; Santos, W.L. Regio- and Chemoselective Diboration of Allenes with Unsymmetrical Diboron: Formation of Vinyl and Allyl Boronic Acid Derivatives. ACS Catal. 2015, 5, 2172-2176. [CrossRef]

32. Miralles, N.; Cid, J.; Cuenca, A.B.; Carbo, J.J.; Fernandez, E. Mixed diboration of alkenes in a metal-free context. Chem. Commun. 2015, 51, 1693-1696. [CrossRef]

33. Cuenca, A.B.; Cid, J.; García-López, D.; Carbó, J.J.; Fernández, E. Unsymmetrical 1,1-diborated multisubstituted $\mathrm{sp}^{3}$-carbons formed via a metal-free concerted-asynchronous mechanism. Org. Biomol. Chem. 2015, 13, 9659-9664. [CrossRef] [PubMed]

34. Krautwald, S.; Bezdek, M.J.; Chirik, P.J. Cobalt-Catalyzed 1,1-Diboration of Terminal Alkynes: Scope, Mechanism, and Synthetic Applications. J. Am. Chem. Soc. 2017, 139, 3868-3875. [CrossRef]

35. Cid, J.; Carbó, J.J.; Fernández, E. A Clear-Cut Example of Selective BpinðBdan Activation and Precise Bdan Transfer on Boron Conjugate Addition. Chem. A Eur. J. 2014, 20, 3616-3620. [CrossRef]

36. Cascia, E.L.; Sanz, X.; Bo, C.; Whiting, A.; Fernandez, E. Asymmetric metal free $\beta$-boration of $\alpha$, $\beta$-unsaturated imines assisted by (S)-MeBoPhoz. Org. Biomol. Chem. 2015, 13, 1328-1332. [CrossRef]

37. Yoshida, H.; Takemoto, Y.; Takaki, K. A masked diboron in Cu-catalysed borylation reaction: Highly regioselective formal hydroboration of alkynes for synthesis of branched alkenylborons. Chem. Commun. 2014, 50, 8299-8302. [CrossRef] [PubMed] 
38. Nelson, A.K.; Peck, C.L.; Rafferty, S.M.; Santos, W.L. Chemo-, Regio-, and Stereoselective Copper(II)-Catalyzed Boron Addition to Acetylenic Esters and Amides in Aqueous Media. J. Org. Chem. 2016, 81, 4269-4279. [CrossRef]

39. Yoshida, H.; Takemoto, Y.; Takaki, K. Borylstannylation of alkynes with inverse regioselectivity: Copper-catalyzed three-component coupling using a masked diboron. Chem. Commun. 2015, 51, 6297-6300. [CrossRef]

40. Takemoto, Y.; Yoshida, H.; Takaki, K. Copper-Catalyzed Three-Component Borylstannylation of Alkynes. Chem. A Eur. J. 2012, 18, 14841-14844. [CrossRef]

41. Sakae, R.; Hirano, K.; Satoh, T.; Miura, M. Copper-Catalyzed Stereoselective Aminoboration of Bicyclic Alkenes. Angew. Chem. Int. Ed. 2014, 54, 613-617. [CrossRef] [PubMed]

42. Sakae, R.; Hirano, K.; Miura, M. Ligand-Controlled Regiodivergent Cu-Catalyzed Aminoboration of Unactivated Terminal Alkenes. J. Am. Chem. Soc. 2015, 137, 6460-6463. [CrossRef] [PubMed]

43. Nishikawa, D.; Hirano, K.; Miura, M. Copper-Catalyzed Regio- and Stereoselective Aminoboration of Alkenylboronates. Org. Lett. 2016, 18, 4856-4859. [CrossRef] [PubMed]

44. Kageyuki, I.; Osaka, I.; Takaki, K.; Yoshida, H. Copper-Catalyzed B(dan)-Installing Carboboration of Alkenes. Org. Lett. 2017, 19, 830-833. [CrossRef] [PubMed]

(C) 2019 by the authors. Licensee MDPI, Basel, Switzerland. This article is an open access article distributed under the terms and conditions of the Creative Commons Attribution (CC BY) license (http:/ / creativecommons.org/licenses/by/4.0/). 